\title{
Original Article \\ Study of Using Foley catheter for Tubularizing Neourethra in Urethroplasty for Hypospadias in Children
}

\author{
Author \\ Dr Nirmal Bhaskar \\ MS, MCh Associate Professor, Dept of Paediatric Surgery, Govt Medical College, Thrissur Kerala \\ Corresponding Author \\ Dr Nirmal Bhaskar \\ Nirmallya House, Gayathri Avenue, Koorkenchery .P.O., Thrissur, 680007 Kerala \\ Phone 9846898030, Email: nirmalbhaskar321@ gmail.com
}

\begin{abstract}
Introduction: Hypospadias is a birth abnormality of the urethra where the urinary opening is not at the usual location on the head of the penis. Treatment of hypospadias is urethroplasty.

Objective: Study the effect of foley catheter for tubularizing neourethra in urethroplasty for hypospadias in children. Usually infant feeding tube is used.

Materials and Methods: This is a prospective study of 2 years duration. Total there were 22 children. Only snodgrass urethroplasty and Dennis Brown urethroplasty were studied. Foley catheter of No:8 used in 14 cases and No:10 Foley's is used in 8 case. We had 1 year follow up.

Result: Of 14 cases in which No:8 foley catheter used, 11 cases had uneventful post operative period. 3 cases with No: 8 Foley used, there was catheter block on 3-5th day and we had to do Suprapubic catheterisation. Of 10 cases in which foley catheter used, all cases had uneventful post operative period. Both cases catheter kept for 2- 3 weeks. None developed urethral fistula or stricture.

Conclusion: Our study shows foley catheter is a good alternative for infant feeding tube, in case of urethroplasty for hypospadias in children. If we use foley catheter No: 8, there is some risk of catheter block. If we can use Foley catheter No:10, result is excellent, without any catheter block. But in both cases, there is no cases of catheter slipping out.Catheter stayed for 3 weeks. All cases had good results.

Keywords: Hypospadias, Urethroplasty, Foley Catheter, Urethral Fistula, infant feeding tube, urethral stricture.
\end{abstract}

\section{Introduction}

Hypospadias is a birth abnormality of the urethra where the urinary opening is not at the usual location on the head of the penis. It is the secondmost common birth abnormality of the male reproductive system, affecting about one of every 250 males at birth ${ }^{[1]}$ Hypospadias is among the most common birth defects in the world and is said to be the second-most common birth defect in the male reproductive system, occurring once in every 250 males ${ }^{[2]}$. Hypospadias is thought to result from failure of the urinary channel to completely tubularize to the end of the penis; the cause is not known. Most often, it is the only abnormal finding, 
although in about $10 \%$ of cases, hypospadias may be part of a syndrome with multiple abnormalities [3][4]

In 2000, Baskin proposed a theory in which the urethral folds fuse to form a seam of epithelium, which is then transformed into mesenchyme and subsequently canalizes by apoptosis or programmed cell resorption ${ }^{[5]}$ Similarly, this seam theoretically also develops at the glanular level, and the endoderm differentiates to ectoderm with subsequent canalization by apoptosis.

The prepuce normally forms as a ridge of skin from the corona that grows circumferentially, fusing with the glans. Failure of fusion of the urethral folds in hypospadias impedes this process, and a dorsal hooded prepuce results.

Chordee (ventral curvature of the penis) is often associated with hypospadias, especially more severe forms. This is thought to result from a growth disparity between the normal dorsal tissue of the corporal bodies and the attenuated ventral urethra and associated tissues. Rarely, the abortive spongiosal tissue and fascia distal to the urethral meatus forms a tethering fibrous band that contributes to the chordee.

In most cases, the foreskin is also underdeveloped and does not wrap completely around the penis, leaving the underside of the glans penis uncovered. Also, a downward bending of the penis, commonly referred to as chordee may occur ${ }^{[6]}$. This is found in $10 \%$ of distal hypospadias ${ }^{[7]}$ and $50 \%$ of proximal hypospadias ${ }^{[8]}$ at the time of surgery.

Hypospadias repair can be done in full-term, healthy infants at any time from 3 months of age. Premature babies generally have surgery done at 6 months or older. Using these guidelines, most babies can undergo repair as same-day surgery, without need to stay in the hospital afterwards.

The results of surgery are probably not influenced by the age at which repair is done, ${ }^{[9][10]}$ but older children are more likely to recall the event.

Today, the most common operation, known as the tubularized incised plate or Snodgrass Urethroplasty, rolls the urethral plate from the low meatus to the end of the glans. This procedure can be used for all distal hypospadias repairs, with complications afterwards expected in less than $10 \%$ of cases ${ }^{[11][12]}$

Less consensus exists regarding proximal hypospadias repair ${ }^{[13]}$. TIP repair (Snodgrass Urethroplasty) can be used when the penis is straight or has mild downward curvature, with success in $85 \%{ }^{[14]}$. Alternatively, the urinary channel can be reconstructed using the foreskin, with reported success in from $55 \%$ to $75 \%{ }^{[15][16]}$.

Most distal and many proximal hypospadias are corrected in a single operation. However, those with the most severe condition having a urinary opening in the scrotum and downward bending of the penis are often corrected in a two-stage operation. During the first operation the curvature is straightened. That is chordee correction. At the second, the urinary channel is completed. One method of Second stage urethroplasty is Dennis Brown Urethroplasty. Here urethral tube is made from penile skin. Second layer with surrounding tissue or Tunica vaginalis flap. Final layer by Penile skin,

Whatever be the type of urethroplasty, the neourethra is made over a tube. Usually Infant feeding tube of size 6 or 8 is used. If we are using infant feeding tube, catheter block is less, as well as can be relieved by flushing with saline. But at the same time catheter slipping out is a common problem for infant feeding tube. Sometimes infant feeding tube can get knotted inside the bladder, which create problem to neourethra while removing. Most children having hypospadias repair heal without complications. This is especially true for distal hypospadias operations, which are successful in over $90 \%$ of cases.

Problems that can arise include a small hole in the urinary channel below the meatus, called a fistula. The new urinary opening can scar, resulting in meatal stenosis or internal scarring can create a stricture, either of which cause partial blockage to urinating. If the new urinary channel balloons when urinating a child is diagnosed with a diverticulum. 


\section{Materials and Method}

Objective is to study the effect of foley catheter for tubularizing neourethra in urethroplasty for hypospadias in children. Usually infant feeding tube No:6 or 8 is used for tubularizing neourethra during urethroplasty in children. This is a prospective study of 2 years duration. Total there were 22 cases. Ages of patients range from 1.5yrs to 10yrs. Only cases with Snodgrass urethroplasty and Dennis Brown urethroplasty were studied. Foley catheter of No:8 used in 14 cases and No:10 Foley's is used in 8 cases, depending upon the size of urethra. Foley catheter no: 8 was the lowest size available to us. So urethroplasty done in small urethra that cannot be inserted with No: 8 Foley are excluded from the study. Since those cases could be done only with infant feeding tube No:6. We had specifically looked for immediate post operative complication like catheter slipping out, catheter block, bladder irritation urethral fistula as well as delayed complications like urethral fistula, urethral stricture and urethral diverticulum. We had followed up for the patient for 1 year.

\section{Results}

Total 22 cases were there. Of 14 cases in which No:8 Foley Catheter used, 11 cases had uneventful post operative period. Catheter kept for 2-3 weeks. But in 3 cases with No: 8 Foley used, there was catheter block on 3-5th day and we had to go for Suprapubic catheterisation for them. (5 cases had simple catheter block, which was relieved by flushing with saline.). Of 8 cases in which No; 10 Foley Catheter used 6 cases had uneventful post operative period. 2 cases had simple catheter block which was relieved by flushing with saline. Catheter was kept for 2-3 weeks. No case had catheter slipping out. No case had bladder irritation. On one year follow up no case developed urethral fistula, urethral stricture and urethral diverticulum.

\section{Discussion}

Our study shows Foley Catheter is a good alternative for infant feeding tube, in case of urethroplasty for hypospadias in children. If we use
Foley Catheter No: 8, there is some risk of catheter block. If we can use Foley catheter No;10 as in big children, result is excellent, without any catheter block. But in both cases, there is no cases of catheter slipping out and bladder irritation .Catheter stayed for 2- 3 weeks. All the cases had good result, without any urethral fistula, urethral stricture and urethral diverticulum. If we are using infant feeding tube, catheter block is less, as well as can be relieved by flushing with saline. But at the same time catheter slipping out is a common problem for infant feeding tube. Sometimes infant feeding tube can get knotted inside the bladder, which create problem to neourethra while removing. In foley catheter, slipping out as well as getting knotted inside bladder are rare. Most of the catheter block can be tackled with flushing with saline. We could keep the foley catheter for longer period (2-3 weeks), which helped for good healing without any fistula, stricture or diverticulum.

\section{References}

1. Snodgrass, Warren (2012). "Chapter 130: Hypospadias". In Wein, Allan. CampbellWalsh Urology, Tenth Edition. Elsevier. pp. 3503-3536. ISBN 978-1-4160-6911-9.

2. Gatti, John M. "Epidemiology". Medscape Reference. Retrieved 22 January 2013.

3. Stoll, C; Alembik, Y; Roth, M P; Dott, B (1990). "Genetic and environmental factors in hypospadias". Journal of Medical Genetics. 27 (9):559. doi:10.1136/jmg.27.9. 559. PMID 2231648.

4. Calzolari, E; Contiero, M R; Roncarati, E; Mattiuz, P L; Volpato, S (1986). "Aetiological factors in hypospadias". Journal of Medical Genetics. 23 (4): 333. doi:10.1136/jmg.23.4.333. PMID 3746833.S.

5. Baskin LS. Hypospadias and urethral development. J Urol. 2000 Mar. 163(3):9516. [Medlin.

6. King, Sebastian \& Beasley, Spencer (2012) [1st. Pub. 1986]. "Chapter 9.1:Surgical Conditions in Older Children". In South, Mike. Practical Paediatrics, Seventh Edition. 
Churchill Livingstone, Elsevier. pp. 266267. ISBN 978-0-702-04292-8.

7. Wein, Allan, ed. (2012). "Chapter 130: Hypospadias". Campbell-Walsh Urology , Tenth Edition. Elsevier. pp. 35033536. ISBN 978-1-4160-6911-9.

8. Snodgrass, W; Prieto, J (2009). "Straightening ventral curvature while preserving the urethral plate in proximal hypospadias repair". The Journal of Urology. 182 (4 Suppl): $\quad$ 1720-5. doi:10.1016/j.juro.2009.02.084. PMID 19692004.

9. https://books.google.com/books?id=6v7MpS AqbgcC\&lpg=PA152\&ots=ujZSvJ01vD\&d q=Bush $\% 20$ et $\% 20 \mathrm{al} \% 2 \mathrm{C} \% 20 \mathrm{~J} \% 20$ Pediatr\% 20Urol\%2C\%202012\&pg=PA117\#v=onepa ge\&q=Bush\%20et\%20al,\%20J\%20Pediatr\% 20Urol, $\% 202012 \& \mathrm{f}=$ false

10. Bush, N.; Snodgrass, W. (2014). "Response to "Re: Snodgrass W, et al. Duration of follow-up to diagnose hypospadias urethroplasty complications. J Pediatr Urol 2014;10:783-784"'. Journal of Pediatric Urology. 10 (4): $\quad$ 784. doi:10.1016/j.jpurol.2014.04.022. PMID 24999242.

11. Snodgrass, Warren T.; Bush, Nicol; Cost, Nicholas (2010). "Tubularized incised plate hypospadias repair for distal hypospadias". Journal of Pediatric Urology. 6 (4): 408. doi:10.1016/j.jpurol.2009.09.010. PMI D 19837000.

12. Wilkinson, David J.; Farrelly, Paul; Kenny, Simon E. (2012). "Outcomes in distal hypospadias: A systematic review of the Mathieu and tubularized incised plate repairs". Journal of Pediatric Urology. 8 (3): 307. doi:10.1016/j.jpurol.2010.11.008. PMI D 21159560

13. Castagnetti, M; El-Ghoneimi, A (2010). "Surgical management of primary severe hypospadias in children: Systematic 20-year review". The Journal of Urology. 184 (4): 1469-74. doi:10.1016/j.juro.2010.-

06.044. PMID 20727541
14. Snodgrass, W. T.; Bush, N; Cost, N (2010). "Tubularized incised plate hypospadias repair for distal hypospadias". Journal of Pediatric Urology. 6 (4): 40813. doi:10.1016/j.jpurol.2009.09.010. PMID 19837000

15. https://books.google.com/books?id=6v7Mp SAqbgcC\&pg=PA129\&lpg=PA129\&dq=De + Mattos+e+Silva+et+al\&source=bl\&ots=uj ZSvJ1-

yC\&sig=oVPygVXNARQ4Zcv3RYHmkjG $\mathrm{g}-$

$\mathrm{fE} \& \mathrm{hl}=\mathrm{en} \& \mathrm{sa}=\mathrm{X} \& \mathrm{ei}=\mathrm{gPcmVfaCEcLkoAS0}$ 34HgCQ \&ved=0CB4Q6AEwAA\#v=onepag e\&q=De $\% 20$ Mattos $\% 20 \mathrm{e} \% 20$ Silva $\% 20 \mathrm{et} \%$ 20 al $\& \mathrm{f}=$ false

16. https://books.google.com/books?id=bNz1B QAAQBAJ\&lpg=PT33\&ots=yoUfYeoJOr\& $\mathrm{dq}=$ Braga $\% 20 \mathrm{et} \% 20 \mathrm{al} \% 2 \mathrm{C} \% 20 \mathrm{~J} \% 20$ Pediatr $\% 20 \mathrm{Urol} \% 2 \mathrm{C} \% 202007 \& \mathrm{pg}=\mathrm{PP} 1 \# \mathrm{v}=$ onepag e\&q=Braga \%20et $\% 20$ al, \%20J\%20Pediatr $\%$ 20Urol, $\% 202007 \& \mathrm{f}=$ false 